\title{
High performance green barriers based on nanocellulose
}

\author{
Sandeep S Nair ${ }^{1}$, JY Zhu², Yulin Deng ${ }^{3}$ and Arthur J Ragauskas ${ }^{4^{*}}$
}

\begin{abstract}
With the increasing environmental concerns such as sustainability and end-of-life disposal challenges, materials derived from renewable resources such as nanocellulose have been strongly advocated as potential replacements for packaging materials. Nanocellulose can be extracted from various plant resources through mechanical and chemical ways. Nanocellulose with its nanoscale dimensions, high crystalline nature, and the ability to form hydrogen bonds resulting in strong network makes it very hard for the molecules to pass through, suggesting excellent barrier properties associated with films made from these material. This review paper aim to summarize the recent developments in various barrier films based on nanocellulose with special focus on oxygen and water vapor barrier properties.
\end{abstract}

Keywords: Green barriers, Nanocellulose, Cellulose nanofibrils, Cellulose nanocrystals

\section{Introduction}

Packaging materials are widely used to prevent food and drink, healthcare, cosmetics and other consumer goods against physical, biochemical, and microbiological deterioration. They should provide sufficient barrier against oxygen, water vapor, grease, and microorganisms. Currently, the packaging materials are largely based on glass, aluminum and tin, and fossil derived synthetic plastics. These materials possess high strength and barrier properties. However, they are unsustainable, some are fragile such as glass, and their weight adds to energy costs for shipping [1-6]. The global consumer packaging demand is valued at approximately US $\$ 400 \mathrm{~b}-\$ 500 \mathrm{~b}$ and is one of the faster-growing markets, forecasted to grow at $\sim 4 \%$ per year until 2015 [7].

With the increased environmental concerns over sustainability and end-of-life disposal challenges, materials derived from renewable resources have been strongly advocated as potential replacements [8]. Cellulose is the most abundant polymer in nature and accounts for approximately $40 \%$ of lignocellulosic biomass. Cellulose paper-based packaging is lightweight, low-cost, and

\footnotetext{
* Correspondence: aragausk@utk.edu

${ }^{4}$ Department of Chemical and Biomolecular Engineering, Department of Forestry, Wildlife, and Fisheries, Center for Renewable Carbon, University of Tennessee, Knoxville, TN 37996-2200, USA

Full list of author information is available at the end of the article
}

most important, sustainable. Unfortunately, common paper made from lignocelluloses does not provide sufficient barrier for water, oxygen or oil. Currently, paper based packages are made with unsustainable coatings of wax, plastics, or aluminum. Cellophane is the only cellulose based material (not modified or coated) currently used for barrier packaging due to its high gas barrier. However, the production of cellophane is via a viscose route which produces byproducts and uses reagents $\left(\mathrm{CS}_{2}\right.$ and $\mathrm{H}_{2} \mathrm{~S}$ ) that are harmful to the environment [9].

The production of cellulose nanomaterial such as cellulose nanofibrils ( $\mathrm{CNFs}$ ) and cellulose nanocrystals (CNCs) have opened vast possibilities of utilizing cellulose based materials for packaging. Cellulose nanomaterial has diameter in the range of $2-50 \mathrm{~nm}$ with large surface area [10-12]. The ability to form hydrogen bonds resulting in strong network makes it very hard for the molecules to pass through, excellent for barrier applications [13]. This review paper aim to summarize the recent developments in various barrier films based on nanocellulose with special focus on oxygen and water vapor barrier properties.

\section{Nanocellulose and its preparation}

Cellulose nanofibrils (CNFs) or microfibrils have diameter in the range of $2-50 \mathrm{~nm}$ and lengths up to several 
micrometers depending on their origin [10-12]. CNFs have exceptional optical and mechanical properties, and therefore can be used as a building block for a variety of high-performance materials [14-16]. Intensive mechanical treatment is required to disintegrate the cellulose fiber to nanofibrils [17]. Several methods of mechanical fibrillation have been used for the production of CNFs such as homogenizers [18,19], microfluidizers [20], and grinders $[21,22]$. Cellulose nanocrystals (CNCs) are often prepared by treating cellulose fiber with sulfuric acid or hydrochloric acid. Strong acidic condition leads to aggressive hydrolysis to attack the noncrystalline fractions within the cellulose fiber which results in the formation of low aspect cellulose fibril aggregates known as $\mathrm{CNCs}$ [23-25].

Mechanical fibrillation of cellulose fibers to CNFs are very energy intensive with reported values ranging from $4500-10000 \mathrm{kWh} /$ tonne [21,22]. Chemical pretreatments and enzymatic pretreatments before mechanical fibrillation have been used to reduce this energy consumption. Cellulose fibers were oxidized by a 2,2,6,6-tetramethylpiperidine-1-oxyl radical (TEMPO)-mediated system. These treated fibers were further mechanically fibrillated to CNFs while reducing the energy costs [26]. Aulin et al. [27] carboxymethylated softwood pulp and then fibers were mechanically fibrillated using a high-pressure fluidizer to produce CNFs of diameter of 5-10 nm. Enzyme pretreatment of biomass followed by mechanical homogenization has been used as an environmentally friendly alternative to chemical pretreatment for nanocellulose production [28-30]. Figure 1 shows the morphological difference between the CNCs and CNFs.

\section{Migration process of molecules through nanocellulose film}

Migration of molecules between two adjacent volumes separated by a thin film of solid polymer or membrane occurs in three basic steps. In the first step, the diffusing molecule is adsorbed on to the sample surface. In the second step, the molecule then diffuses through the film or membrane. Finally, the diffusing molecule exits the sample by desorbing from the surface. The gas permeability through a nanocellulose film mainly depends on the dissolution of gas and its rate of diffusion in the film. Thus, permeability of gas molecules through nanocellulose film can be expressed as:

$$
\mathrm{P}=\mathrm{DS}
$$

Where $\mathrm{P}$ is the permeability, $\mathrm{D}$ is the diffusion coefficient, and $\mathrm{S}$ is the solubility coefficient.

The permeability coefficient $\mathrm{P}$ is obtained from the application of Henry's law of solubility to Fick's law of diffusion,

$$
\mathrm{P}=\mathrm{DS}=\mathrm{ql} / \mathrm{At} \Delta \mathrm{p}
$$

Where $\mathrm{q}$ is the amount of material passing through the film, $\mathrm{l}$ is the thickness, A is the cross sectional area, $\mathrm{t}$ is time, and $\Delta \mathrm{p}$ is the pressure difference between the two sides of film.

The gas molecules should be first dissolved in the membrane or film before diffusing. Even though the surface of films influences the permeating gas molecules, the most dominant factor in molecular migration is bulk flow, i.e., rate of molecule diffusion in the membrane or film [31]. The good oxygen barrier properties of nanocellulose can be attributed to the dense network formed by nanofibrils with smaller and more uniform dimensions. Considering this fact, the pores within the films serve as the major path for permeating oxygen molecules. The dense nanofibrils forms more complex and smaller pores compared to pure cellulose fibers which are in micro scale. This complex dense network increases the tortuosity within the film and thereby decreases the permeability within the films [13]. Figure 2 shows a schematic

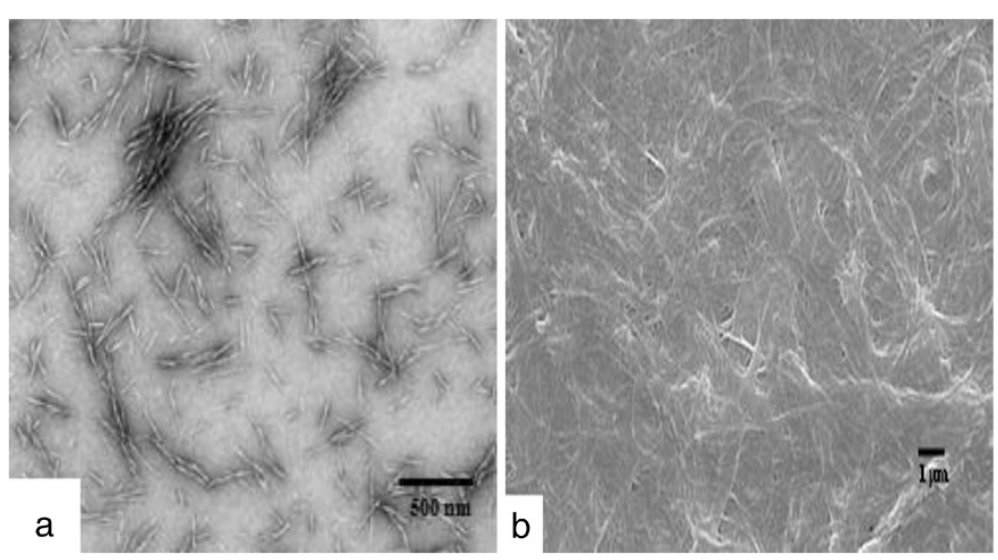

Figure 1 Images of (a) CNCs [24], and (b) CNFs [18]. 


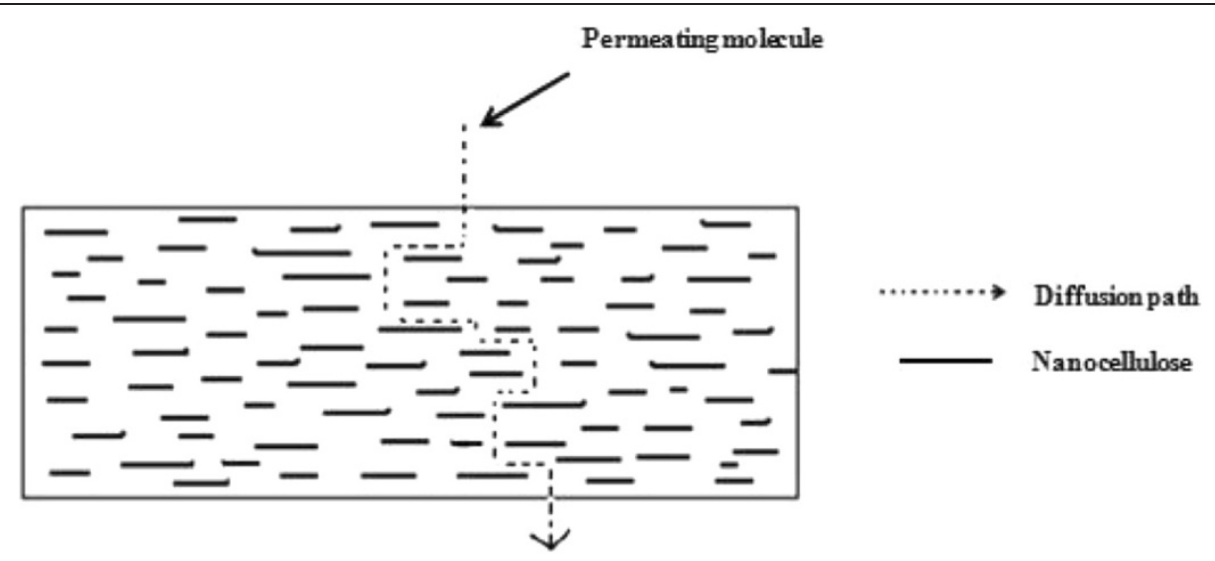

Figure 2 Shows schematic representation of increased diffusion path within the nanocellulose films.

representation of increased diffusion path within the nanocellulose films. Also, the high crystalline structure within the nanofibrils or whiskers contributes to the gas barrier properties [23,31]. Cellulose is composed of both crystalline and disordered regions. High crystallinity ranging from $40-90 \%$ has been reported for the nanocellulose, with $\mathrm{CNCs}$ showing higher crystallinity than the CNFs because strong acid hydrolyzes disordered cellulose to result in highly crystalline CNCs [21,32]. Even though the CNCs have higher crystallinity than CNFs, mechanically fibrillated CNF films were found to have much lesser oxygen permeability than CNCs. Both showed similar solubility, but the oxygen molecules penetrated more slowly though the CNF films. This is mainly due to the structural organization within the films. The CNF films have higher entanglements within the film which increased the tortuosity factor or increase the diffusion path [33]. Even though nanocellulose provides a high barrier for oxygen, the water vapor barrier properties are low. This is mainly due to high affinity between water and the nanocellulose film. Nanocellulose is much better water vapor barrier than cellulose fiber. Nanocellulose has a strong reducing effect on water vapor diffusion due to its size, and swelling constraints formed due to rigid network within the films. However, at a high relative humidity these structural organizations can be disrupted due to high swelling and can lose barrier properties for both oxygen and water vapor [34].

\section{CNFs for barrier application}

CNFs is a strong gas barrier material. Compared to CNCs, CNFs consists of crystalline and disordered regions. In most of the cases, crystallinity ranging from $40-75 \%$ has been reported for the CNFs obtained from softwoods and hardwoods [11,12,21,22]. Saito and Isogai (2004) showed that the degree of crystallinity varied from $78-91 \%$ for
CNFs produced from TEMPO oxidation of cotton linter [35]. Films made purely of mechanically fibrillated CNFs have very high air and oxygen barrier property. The oxygen transmission rates (OTR) of CNF films with thickness of $21 \mu \mathrm{m}$ were as low as $17 \pm 1 \mathrm{ml} \mathrm{m}^{-2}$ day $^{-1}$. These values are competitive with other best synthetic polymers such as ethylene vinyl alcohol (EVOH) (3-5 $\mathrm{ml} \mathrm{m}^{-2}$ day $^{-1)}$ and polyvinylidene chloride (PVdC) coated polyester films $\left(9-15 \mathrm{ml} \mathrm{m}^{-2}\right.$ day $\left.^{-1}\right)$ of approximately same thickness with respect to OTR [13]. Recently, Osterberg et al. [36] demonstrated a rapid method of making robust CNF films with high oxygen barrier property. The CNF solutions were first filtered followed by hot pressing at high pressure followed by air drying. At a relative humidity below $65 \%$, the oxygen permeability of these films was below $0.6 \mathrm{~cm}^{3} \mu \mathrm{m} \mathrm{m}^{-2} \mathrm{~d}^{-1} \mathrm{kPa}^{-1}$. However, oxygen permeability of CNF films increases with the increase in relative humidity. This is mainly due to the plasticizing and swelling of nanofibrils through the adsorption of water molecules at high relative humidities.

CNFs also have tunable barrier properties. Rodionova et al. [5] showed that both pure and partially acetylated CNF films can be used for modified atmosphere packaging (MAP) with permeability below $10-20 \mathrm{~mL} \mathrm{~m}^{-2}$ day $^{-1}$. Similarly, carboxymethylated CNF films with thicknesses of 2.54 and $3.19 \mu \mathrm{m}$ have very low oxygen permeability of 0.009 and $0.0006 \mathrm{~cm}^{3} \mu \mathrm{m} \mathrm{m}^{-2}$ day ${ }^{-1} \mathrm{kPa}^{-1}$, respectively [27]. High oxygen performance barrier films with permeability of $0.007 \mathrm{~cm}^{3} \mu \mathrm{m} \mathrm{m}^{-2}$ day ${ }^{-1} \mathrm{kPa}^{-1}$ can be made by controlled thermal treatment at different temperatures. It was demonstrated that after thermal treatment at $175^{\circ} \mathrm{C}$, the oxygen permeability of the CNF films was reduced by 96\% compared to the films without heat treatment [37]. Table 1 shows the oxygen permeability of films made from nanocellulose compared with those from commercially available petroleum based materials and other polymers. Also, CNFs are used to coat the surface of films to 


\begin{tabular}{|c|c|c|}
\hline Material & $\begin{array}{l}\text { Oxygen permeability } \\
\left(\mathrm{cc} . \mu \mathrm{m} / \mathrm{m}^{2} . \text { day.kPa) }\right.\end{array}$ & $\begin{array}{l}\text { References, } \\
\text { conditions }\end{array}$ \\
\hline CNF & 0.6 & [35], at $65 \% \mathrm{RH}$ \\
\hline CNF (carboxymethylated) & 0.0006 & {$[27]$, at $0 \% \mathrm{RH}$} \\
\hline CNF (carboxymethylated) & 0.85 & [27], at $50 \% \mathrm{RH}$ \\
\hline Cellophane & 0.41 & {$[46]$, at $0 \% \mathrm{RH}$} \\
\hline PVdC & $0.1-3$ & [47], at $50 \% \mathrm{RH}$ \\
\hline Polyvinyl alcohol (PVOH) & 0.20 & [47], at $0 \% \mathrm{RH}$ \\
\hline $\mathrm{EVOH}$ & $0.01-0.1$ & [47], at $0 \% \mathrm{RH}$ \\
\hline
\end{tabular}

enhance the barrier properties. Fukuzumi et al. [38] prepared high oxygen barrier CNF films by TEMPO mediated oxidation. The $0.1 \mu \mathrm{m}$ thick CNF film when coated on a polylactic acid film, reduced the oxygen permeability from $746 \mathrm{ml} \mathrm{m}^{-2}$ day $^{-1} \mathrm{~Pa}^{-1}$ for pure PLA film to $1 \mathrm{ml} \mathrm{m}^{-2}$ day $^{-1} \mathrm{~Pa}^{-1}$ for PLA film with CNF layer. The oxygen barrier of PET films was raised by more than 350 times through a $1 \mu \mathrm{m}$ thick layer of the same TEMPO-oxidized CNFs [39]. Similarly, Fujisawa et al. [40] found that the use of TEMPO-oxidized CNFs with sodium carboxylate groups improved the oxygen barrier of PET films more than when coated with TEMPO-oxidized CNFs with carboxyl groups. Hult et al. [41] showed that the oxygen transmission rate of paper substrates were decreased by several logarithmic units by the deposition of CNFs and shellac coating layers. CNFs have also been used as filler material to obtain a nanocomposite material. Plackett et al. [42] showed that the addition of $15 \mathrm{wt} \%$ of CNFs substantially increased the oxygen barrier of amylopectin films. The use of CNFs in xylan films showed very low oxygen permeability of $0.19 \mathrm{~cm}^{3} \mu \mathrm{m} \mathrm{m}^{-2}$ day $^{-1} \mathrm{kPa}$, which is comparable to previously reported values for $100 \%$ CNF films [43]. Several studies have been conducted on making composites using CNF with nanoclay [44], and talc [45]. Oxygen barrier properties of these composites were highly competitive and much better than various synthetic polymers currently used in the packaging industry.

Even though the oxygen barrier properties of CNF films are competitive with current commercial films made from synthetic polymers, their water vapor barrier remains very low or the water vapor transfer rate remain very high. Table 2 shows the water vapor transmission rate (WVTR) of nanocellulose films than those of commercially available films from petroleum based materials and other polymers. This is mainly due to the strong hydrophilic nature of the cellulose nanofibers. However, the water vapor transmission rate $\left(0.02 \mathrm{~g} / \mathrm{m}^{2}\right.$ day $\left./ \mathrm{m}\right)$ was significantly lower compared with films made from bleached softwood fibers $\left(0.11 \mathrm{~g} / \mathrm{m}^{2}\right.$ day $\left./ \mathrm{m}\right)$. The CNF film structure is more compact, therefore less water can penetrate through the film compared to the films made of cellulose fibers. The water contact angle was substantially increased for the CNF film compared to films made from bleached softwood film. The hydrophilic nature is not the only important criteria for water vapor barrier property. The films with high lignin content created more hydrophobic surface with higher water contact angles but showed the least water vapor barrier enhancement. However, the CNF films without lignin produced a more compact structure. The presence of lignin hindered the hydrogen bonding and created more hydrophobic pores which aided in more water vapor transmission [34]. Recently, researchers have modified the properties of CNFs using various pretreatments to enhance the water vapor barrier property. Sharma et al. [37] showed that the water vapor permeability was reduced by $50 \%$ upon heat treatment at $175^{\circ} \mathrm{C}$ for 3 hours as compared to the untreated CNF films. They attributed that the enhancement in barrier property was mainly due to increase in hydrophobicity as evidenced by the increase in water contact angle and reduced porosity by heat treatment. Rodionova et al. [5] showed that the WVTR of pure CNF films $\left(234 \mathrm{~g} \mathrm{~m}^{-2}\right.$ day ${ }^{-1}$ ) was reduced to $167 \mathrm{~g} \mathrm{~m}^{-2}$ day ${ }^{-1}$ by 30 mins of acetylation treatment. The acetylation created a much higher hydrophobic film surface indicates by higher water contact angles. Minelli et al. [48] showed that the use of carboxymethylated pretreated CNFs produced a more homogenous and less porous film than enzyme pretreated CNFs and showed a much enhancement in water vapor barrier property below $80 \%$ relative humidity. Recently, the water vapor permeability of the paper substrates was substantially decreased with a multilayer coating of nanocellulose and alkyd resins. The WVTR reached very low and reached values considered as high barriers in packaging applications [49].

\section{CNCs for barrier application}

Contrary to CNFs, very few studies have been directed toward study of $100 \%$ pure CNC film or treated CNC films. Belbekhouche et al. [33] compared the gas barrier properties between $\mathrm{CNF}$ and $\mathrm{CNC}$ films. They found that the films made of $\mathrm{CNCs}$ were more permeable to oxygen than those made of CNFs. The oxygen molecules penetrated much more slowly within CNF film due to the higher fibril entanglements within the film which increased the tortuosity factor. CNCs, which have crystallinity greater than $60 \%$ combined with their ability to form a dense hydrogen bonded network can increase gas barrier property. Bacterial cellulose nanocrystals (BNCs) films present excellent oxygen barrier at low relative humidity, but their high moisture sensitivity results in dramatically decreased barrier when the 
Table 2 WVTR of nanocellulose compared to commercially available petroleum based materials and other polymers

\begin{tabular}{llll}
\hline Material & $\begin{array}{l}\text { Water vapor transmission rate } \\
\left(\text { WVTR) }\left(\mathbf{g} / \mathbf{m}^{2} \text { day) }\right.\right.\end{array}$ & $\begin{array}{l}\text { Average thickness of } \\
\text { the film }(\boldsymbol{\mu m})\end{array}$ & $\begin{array}{l}\text { References, } \\
\text { conditions }\end{array}$ \\
\hline CNF & 234 & 42 & {$[5], 50 \% \mathrm{RH}$} \\
CNF (acetylated for $0.5 \mathrm{~h})$ & 167 & 46 & {$[5], 50 \% \mathrm{RH}$} \\
PVdC & 3.07 & 12.7 & {$[50], 100 \% \mathrm{RH}$} \\
Polyethylene (PE) & 16.8 & 18.3 & {$[50], 100 \% \mathrm{RH}$} \\
Plasticized polyvinyl chloride (PVC) & 118.56 & 12.7 & {$[50], 100 \% \mathrm{RH}$} \\
\hline
\end{tabular}

relative humidity is higher than $70 \%$. The oxygen permeability of $6.99 \times 10^{-22} \mathrm{~m}^{3} \mathrm{~m} / \mathrm{m}^{2} \mathrm{~s}$ Pa at $0 \%$ humidity increased to $5.97 \times 10^{-18} \mathrm{~m}^{3} \mathrm{~m} / \mathrm{m}^{2} \mathrm{~s}$ Pa at $80 \%$ humidity. However, this permeability was reduced by $97 \%$ and $74 \%$ when BNC films were coated with annealed PLA electro spun nanostructured fibers and 3-aminopropyl) trimethoxysilane (APTS), respectively [51]. Herrara et al. [52] studied thin spin coated films made from CNCs prepared with sulfuric acid and hydrochloric acid. The hydrochloric acid made CNCs resulted in films with low permeability for oxygen, while the sulfuric acid made CNCS resulted in films with higher permeability.

CNCs have been studied as filler for various natural polymers for enhancing the barrier properties. Saxena et al. [23] produced nanocomposite film with low oxygen permeability by casting an aqueous solution containing xylan, sorbitol and nanocrystalline cellulose. Oxygen permeability of films prepared from xylan, sorbitol and $50 \%$ by weight of sulfonated CNC exhibited a significantly reduced oxygen permeability of $0.1799 \mathrm{~cm}^{3} . \mu \mathrm{m} / \mathrm{m}^{2}$.d.kPa compared with films prepared solely from xylan and sorbitol with an oxygen permeability of $189.1665 \mathrm{~cm}^{3} . \mu \mathrm{m} / \mathrm{m}^{2}$. d.kPa. Poly lactic acid (PLA) nano-biocomposites containing $5 \mathrm{wt} \%$ of nanocrystals exhibited the highest oxygen barrier. The OTR for PLA nanocomposites with $5 \% \mathrm{w} / \mathrm{w}$ of unmodified CNCs was $17.4 \pm 1.4 \mathrm{~cm}^{3} \mathrm{~mm} \mathrm{~m}^{-2}$ day $^{-1}$, while that for modified CNCs with an acid phosphate ester of ethoxylated nonylphenol in a $1 / 4$ (wt/wt) ratio was $15.8 \pm 0.6 \mathrm{~cm}^{3} \mathrm{~mm} \mathrm{~m}^{-2}$ day $^{-1}$ [53]. Addition of $1 \mathrm{wt} \%$ of silver nanoparticles to these modified CNC- PLA composites further decreased the OTR to $12.6 \pm 0.1 \mathrm{~cm}^{3} \mathrm{~mm} \mathrm{~m}^{-2} \mathrm{day}^{-1}$ [54]. The OTR values of ternary systems consisting of PLA, PHB (poly hydroxybutyrate) and $5 \mathrm{wt} \%$ unmodified CNCs was $15.3 \mathrm{~cm}^{3} \mathrm{~mm} \mathrm{~m}^{-2}$ day $^{-1}$, while that for modified CNCs with an acid phosphate ester of ethoxylated nonylphenol in a $1 / 1$ (wt/wt) ratio was $13 \mathrm{~cm}^{3} \mathrm{~mm} \mathrm{~m}^{-2}$ day $^{-1}$. Water contact angle measurements showed that the ternary system had high hydrophobicity and the presence of sulphate groups with low polarity on the surface of $\mathrm{CNCs}$ increased the surface hydrophobicity of the final composite material [55].
CNCs were used as fillers in polyvinyl alcohol (PVOH) matrix. The addition of $5 \mathrm{wt} \% \mathrm{CNCs}$ decreased the WVP of pure PVOH films from $0.61 \pm 0.04$ g.mm $/ \mathrm{kPa} . h . \mathrm{m}^{2}$ to $0.44 \pm 0.01$ g.mm $/ \mathrm{kPa} . \mathrm{h} . \mathrm{m}^{2}$ [56]. The reinforcement of natural biopolymers with $\mathrm{CNCs}$ was found to reduce WVTR of the resulting nanocomposites. The films prepared using xylan as reinforcement polymer with 10\% sulfonated CNCs exhibited a $74 \%$ reduction in specific water transmission properties compared with the film without CNCs and a $362 \%$ improvement compared with xylan films reinforced by $10 \%$ softwood kraft fibers. The xylan/sulphonated CNC nanocomposites showed a WVTR of $174 \mathrm{~g} / \mathrm{hm}^{2}$ [57]. They also compared xylan films reinforced with $\mathrm{CNC}$ made from hydrochloric acid with those reinforced with sulphonated CNC. Even though, films showed a significant reduction in water transmission, the reduction was not as significant as those using sulfonated CNCs. The xylan/ hydrochloric acid made CNC films showed a WVTR of $281 \mathrm{~g} / \mathrm{hm}^{2}$ [58]. Khan et al. [59] showed that the values of water vapor permeability (WVP) decreased sharply as the content of $\mathrm{CNCs}$ increased in the methyl cellulose based films. The WVP of control films (without CNCs) was $6.3 \mathrm{~g} . \mathrm{mm} / \mathrm{m}^{2}$. day.kPa, while those films in cooperated with $1 \mathrm{wt} \% \mathrm{CNC}$ showed a permeability of $4.7 \mathrm{~g} . \mathrm{mm} / \mathrm{m}^{2}$.day.kPa.

\section{Conclusions}

Nanocellulose such as CNFs and CNCs have opened vast possibilities of utilizing cellulose based materials. The use of CNFs in films, composites, and coatings has found to substantially reduce the oxygen permeability within these materials. The oxygen barrier efficiency of pure CNF films is highly competitive and even be comparable with commercial synthetic polymers. The improvement of oxygen barrier properties by CNFs can be attributed to the dense network formed by nanofibrils with smaller and more uniform dimensions. Even though CNCs have higher crystallinity than CNFs, mechanically fibrillated CNF films were found have much lesser oxygen permeability than CNCs. The CNF films have higher entanglements within the film which increases the diffusion path for gas molecules. Also, nanocellulose has a strong reducing effect on water vapor diffusion due to its size, 
and swelling constraints formed due to rigid network within the films compared to cellulose fibers. The use of CNFs and CNCs in various natural polymer based composites has found to substantially reduce the gas permeability within these composites.

\section{Competing interests}

The authors declared that they have no competing interests.

\section{Authors' contributions}

All the authors have contributed to the literature review and manuscript writing. All authors read and approved the final manuscript.

\section{Acknowledgements}

This work was partially supported by the USDA Forest Service R \& D special funding on Cellulose Nano-Materials (2012).

\section{Author details}

${ }^{1}$ School of Chemistry and Biochemistry, Georgia Institute of Technology, 500 10th Street, N.W, Atlanta, GA 30332, USA. ${ }^{2}$ USDA Forest Service, Forest Products Laboratory, One Gifford Pinchot Drive, Madison, WI 53726, USA. ${ }^{3}$ School of Chemical and Biomolecular Engineering, Georgia Institute of Technology 500 10th Street, N.W, Atlanta, GA 30332, USA. ${ }^{4}$ Department of Chemical and Biomolecular Engineering, Department of Forestry, Wildlife, and Fisheries, Center for Renewable Carbon, University of Tennessee, Knoxville, TN 37996-2200, USA.

Received: 14 July 2014 Accepted: 24 October 2014

Published online: 07 November 2014

\section{References}

1. Bayer IS, Fragouli D, Attanasio A, Sorce B, Bertoni G, Brescia R, Di Corato R, Pellegrino T, Kalyva M, Sabella S, Pompa PP, Cingolani R, Athanassiou A: Water-repellent cellulose fiber networks with multifunctional properties. ACS Appl Mater Interfaces 2011, 3:4024-4031.

2. Hansen NML, Plackett D: Sustainable films and coatings from hemicelluloses: a review. Biomacromolecules 2008, 9:1493-1505

3. Priolo MA, Gamboa D, Holder KM, Grunlan JC: Super gas barrier of transparent polymer - clay multilayer ultrathin films. Nano Lett 2010, 10:4970-4974.

4. Reis AB, Yoshida CMP, Reis APC, Franco TT: Application of chitosan emulsion as a coating on Kraft paper. Polym Int 2011, 60:963-969.

5. Rodionova G, Lenes M, Eriksen O, Gregersen O: Surface chemical modification of microfibrillated cellulose: improvement of barrier properties for packaging applications. Cellulose 2011, 18:127-134.

6. Spence KL, Venditti RA, Rojas OJ, Pawlak JJ, Hubbe MA: Water vapor barrier properties of coated and filled microfibrillated cellulose composite films. BioResources 2011, 6:4370-4388.

7. Neil-Boss N, Brooks K: Unwrapping the packaging industry: seven factors for success. 2013. http://www.ey.com/Publication/uwLUAssets/Unwrapping_the_ packaging_industry_\%E2\%80\%93_seven_factors_for_success/\$FFlLE/EY_ Unwrapping_the_packaging_industry___seven_success_factors.pdf.

8. Nair SS, Wang SQ, Hurley DC: Nanoscale characterization of natural fibers and their composites using contact-resonance force microscopy. Compos Part A 2010, 41:624-631.

9. Hyden WL: Manufacture and properties of regenerated cellulose films. Ind Eng Chem 1929, 21:405-410.

10. Stelte W, Sanadi AR: Preparation and characterization of cellulose nanofibers from two commercial hardwood and softwood pulps. Ind Eng Chem Res 2009, 48:11211-11219.

11. Nair SS, Zhu JY, Deng Y, Ragauskas AJ: Hydrogels prepared from cross-linked nanofibrillated cellulose. ACS Sustainable Chem Eng 2014, 2:772-780,

12. Hoeger IC, Nair SS, Ragauskas AJ, Deng Y, Rojas OJ, Zhu JY: Mechanical deconstruction of lignocellulose cell walls and their enzymatic saccharification. Cellulose 2013, 20:807-818.

13. Syverud K, Stenius P: Strength and barrier properties of MFC films. Cellulose 2009, 16:75-85.

14. Abraham E, Deepa B, Pothan LA, Jacob M, Thomas S, Cvelbar U, Anandjiwala R: Extraction of nanocellulose fibrils from lignocellulosic fibers: a novel approach. Carbohydr Polym 2011, 86:1468-1475.
15. Kaushik A, Singh M: Isolation and characterization of cellulose nanofibrils from wheat straw using steam explosion coupled with high shear homogenization. Carbohydr Res 2011, 346:76-85.

16. He L, Li X, Li W, Yuan J, Zhou H: A method for determining reactive hydroxyl groups in natural fibers:application to ramie fiber and its modification. Carbohydr Res 2012, 348:95-98.

17. Uetani $\mathrm{K}$, Yano $\mathrm{H}$ : Nanofibrillation of wood pulp using a high-speed blender. Biomacromolecules 2011, 12:348-353.

18. Chinga-Carrasco G, Syverud K: On the structure and oxygen transmission rate of biodegradable cellulose nanobarriers. Nanoscale Res Lett 2012, 7:192

19. Chinga-Carrasco G, Kuznetsova N, Garaeva M, Leirset I, Galiullina G, Kostochko A, Syverud K: Bleached and unbleached MFC nanobarriers: properties and hydrophobisation with hexamethyldisilazane. J Nanopart Res 2012, 14:1280.

20. Henriksson M, Berglund LA, Isaksson P, Lindstrom T, Nishino T: Cellulose nanopaper structures of high toughness. Biomacromolecules 2008, 9:1579-1585.

21. Nair SS, Zhu JY, Deng Y, Ragauskas AJ: Charaterization of cellulose nanofibrillation by micro grinding. J Nanopart Res 2014, 16:2349.

22. Wang QQ, Zhu JY, Gleisner R, Kuster TA, Baxa U, McNeil SE: Morphological development of cellulose fibrils of a bleached eucalyptus pulp by mechanical fibrillation. Cellulose 2012, 19:1631-1643.

23. Saxena A, Elder TJ, Kenvin J, Ragauskas AJ: High oxygen nanocomposite barrier films based on xylan and nanocrystalline cellulose. Nano-Micro Lett 2010, 2:235-241.

24. Wang QQ, Zhu JY, Reiner RS, Verril SP, Baxa U, Mc Neil SE: Approaching zero cellulose loss in cellulose nanocrystal (CNC) production: recovery and characterization of cellulosic solid residues (CSR) and CNC. Cellulose 2012, 19:2033-2047.

25. Beck-Candanedo S, Roman M, Gray DG: Effect of reaction conditions on the properties and behavior of wood cellulose nanocrystal suspensions. Biomacromolecules 2006, 6:1048-1054.

26. Saito T, Kimura S, Nishiyama Y, Isogai A: Cellulose nanofibers prepared by TEMPO-mediated oxidation of native cellulose. Biomacromolecules 2007, 8:2485-2491.

27. Aulin C, Gallstedt M, Lindstrom T: Oxygen and oil barrier properties of microfibrillated cellulose films and coatings. Cellulose 2010, 17:559-574.

28. Henriksson M, Henriksson G, Berglund LA, Lindström T: An environmentally friendly method for enzyme-assisted preparation of microfibrillated cellulose (MFC) nanofibers. Eur Polym J 2007, 43:3434-3441.

29. Hayashi N, Kondo T, Ishihara M: Enzymatically produced nano-ordered short elements containing cellulose I-beta crystalline domains. Carbohydr Polym 2005, 61:191-197.

30. Zhu JY, Sabo R, Luo XL: Integrated production of nano-fibrillated cellulose and cellulosic biofuel (ethanol) by enzymatic fractionation of wood fibers. Green Chem 2011, 13:1339-1344.

31. Lagaron JM, Catala R, Gavara R: Structural characteristics defining high barrier properties in polymeric materials. Mater Sci Technol 2004, 20:1-7.

32. Guo J, Catchmark JM: Surface area and porosity of acid hydrolyzed cellulose nanowhiskers and cellulose produced by Gluconacetobacter xylinus. Carbohydr Polym 2012, 87:1026-1037.

33. Belbekhouche S, Bras J, Siqueira G, Chappey C, Lebrun L, Khelifi B, Marais S, Dufresne A: Water sorption behaviour and gas barrier properties of cellulose whiskers and microfibrils films. Carbohydr Polym 2011, 83:1740-1748.

34. Spence KL, Venditti RA, Rojas OJ, Habibi Y, Pawlak JJ: The effect of chemical composition on microfibrillar cellulose films from wood pulps: water interactions and physical properties for packaging applications. Cellulose 2010, 17:835-848

35. Saito T, Isogai A: TEMPO-mediated oxidation of native cellulose. The effect of oxidation conditions on chemical and crystal structures of the water- insoluble fractions. Biomacromolecules 2004, 5:1983-1989.

36. Osterberg M, Vartiainen J, Lucenius J, Hippi U, Seppala J, Serimaa R, Laine J: A fast method to produce strong NFC films as a platform for barrier and functional materials. ACS Appl Mater Interfaces 2013, 5:4640-4647.

37. Sharma S, Zhang X, Nair SS, Ragauskas AJ, Zhu JY, Deng Y: Thermally enhanced high performance cellulose nano fibril barrier membranes. RSC Adv 2014, 4:45136-45142.

38. Fukuzumi H, Saito T, Wata T, Kumamoto Y, Isogai A: Transparent and high gas barrier films of cellulose nanofibers prepared by TEMPO-mediated oxidation. Biomacromolecules 2009, 10:162-165.

39. Rodionova G, Saito T, Lenes M, Eriksen O, Gregersen O, Fukuzumi H, Isogai A: Mechanical and oxygen barrier properties of films prepared from 
fibrillated dispersions of TEMPO-oxidized Norway spruce and Eucalyptus pulps. Cellulose 2012, 19:705-711.

40. Fujisawa S, Okita Y, Fukuzumi H, Saito T, Isogai A: Preparation and characterization of TEMPO-oxidized cellulose nanofibrils films with free carboxyl groups. Carbohydr Polym 2011, 84:579-583.

41. Hult EL, Lotti M, Lenes M: Efficient approach to high barrier packaging using microfibrillar cellulose and shellac. Cellulose 2010, 17:575-586.

42. Plackett $D$, Anturi $H$, Hedenqvist $M$, Ankerfors $M$, Gallstedt $M$, Lindstrom $T$, Siro I: Physical properties and morphology of films prepared from microfibrillated cellulose and microfibrillated cellulose in combination with amylopectin. J Appl Polym Sci 2010, 117:3601-3609.

43. Hansen NML, Blomfeldt TOJ, Hedenqvist MS, Plackett DV: Properties of plasticized composite films prepared from nanofibrillated cellulose and birch wood xylan. Cellulose 2012, 19:2015-2031.

44. Aulin C, Salazar-Alvarez G, Lindstrom T: High strength, flexible and transparent nanofibrillated cellulose - nanoclay biohybrid films with tunable oxygen and water vapor permeability. Nanoscale 2012, 4:6622-6628

45. Liimatainen H, Ezekiel N, Sliz R, Ohenoja K, Sirvio JA, Berglund L, Hormi O, Niinimaki J: High-strength nanocellulose - talc hybrid barrier films. ACS Appl Mater Interfaces 2013, 5:13412-13418.

46. Wu J, Yuan Q: Gas permeability of a novel cellulose membrane. J Membr Sci 2002, 204:185-194.

47. Lange J, Wyser Y: Recent innovations in barrier technologies for plastic packaging -a review. Packag Technol Sci 2003, 16:149-158.

48. Minelli M, Baschetti MG, Doghieri F, Ankerfors M, Lindstrom T, Siro I, Plackett D: Investigation of mass transport properties of microfibrillated cellulose (MFC) films. J Membr Sci 2010, 358:67-75.

49. Aulin C, Strom G: Multilayered alkyd resin/nanocellulose coatings for use in renewable packaging solutions with a high level of moisture resistance. Ind Eng Chem Res 2013, 52:2582-2589.

50. Steven MD, Hotchkiss JH: Comparison of flat film to total package water vapor transmission rates for several commercial food wraps. Packag Technol Sci 2002, 15:17-27.

51. Martinez-Sanz M, Lopez-Rubio A, Lagaron JM: High-barrier coated bacterial cellulose nanowhiskers with reduced moisture sensitivity. Carbohydr Polym 2013, 98:1072-1082.

52. Herrera MA, Mathew AP, Oksman K: Gas permeability and selectivity of cellulose nanocrystals films (layers) deposited by spin coating. Carbohydr Polym 2014, 112:494-501.

53. Fortunati E, Peltzer M, Armentano I, Torre L, Jimenez A, Kenny JM: Effects of modified cellulose nanocrystals on the barrier and migration of PLA nano-composites. Carbohydr Polym 2012, 90:948-956.

54. Fortunati E, Peltzer M, Armentano I, Jimenez A, Kenny JM: Combined effects of cellulose nanocrystals and silver nanoparticles on the barrier and migration properties of PLA nano-biocomposites. J Food Eng 2013, 118:117-124.

55. Arrieta MP, Fortunati E, Dominici F, Rayon E, Lopez J, Kenny JM: PLA-PHB/ cellulose based films: mechanical, barrier and disintegration properties. Polym Degrad Stab 2014, 107:139-149.

56. Pereira ALS, do Nascimento DM, Souza Filho MM, Morais JPS, Vasconcelos NF, Feitosa JPA, Brigida AIS, Rosa MF: Improvement of polyvinyl alcohol properties by adding nanocrystalline cellulose isolated from banana pseudostems. Carbohydr Polym 2014, 112:165-172.

57. Saxena A, Ragauskas AJ: Water transmission barrier properties of biodegradable films based on cellulosic whiskers and xylan. Carbohydr Polym 2009, 78:357-360.

58. Saxena A, Elder TJ, Ragauskas AJ: Moisture barrier properties of xylan composite films. Carbohydr Polym 2011, 84:1371-1377.

59. Khan RA, Salmieri S, Dussault D, Uribe-Calderon J, Kamal MR, Safrany A, Lacroix M: Production and properties of nanocellulose-reinforced methycellulose-based biodegradable films. J Agric Food Chem 2010, 58:7878-7885.

Publish with ChemistryCentral and every
scientist can read your work free of charge
"Open access provides opportunities to our
colleagues in other parts of the globe, by allowing
anyone to view the content free of charge."
W. Jeffery Hurst, The Hershey Company.
- available free of charge to the entire scientific community
- peer reviewed and published immediately upon acceptance
- cited in PubMed and archived on PubMed Central
- yours - you keep the copyright
submit your manuscript here:
http://www.chemistrycentral.com/manuscript/

